\title{
Psychological impact of COVID-19 on obstetrics and gynaecology residents in India
}

\author{
Shail Prasad $^{1 *}$, Chandrashekhar Mahato², Navneet Magon ${ }^{3}$
}

\begin{abstract}
${ }^{1}$ Department of Reconstructive and Cosmetic Gynecology, All India Institute of Medical Sciences Rishikesh, Uttarakhand, India

${ }^{2}$ Department of Health, Central Health Services, Central Institute of Psychiatry, Ranchi, India

${ }^{3}$ Division of Reconstructive and Cosmetic Gynecology, and Additional Medical Superintendent COVID-19 care centre, All India Institute of Medical Sciences Rishikesh, Uttarakhand, India
\end{abstract}

Received: 15 May 2021

Accepted: 04 June 2021

\author{
*Correspondence: \\ Dr. Shail Prasad, \\ E-mail: drshailprasad6@gmail.com
}

Copyright: ( ) the author(s), publisher and licensee Medip Academy. This is an open-access article distributed under the terms of the Creative Commons Attribution Non-Commercial License, which permits unrestricted non-commercial use, distribution, and reproduction in any medium, provided the original work is properly cited.

\section{ABSTRACT}

Background: New emerging coronavirus strains are responsible for the rampant spread of COVID-19. This pandemic is not only associated with detrimental health but also with low socio-economic and adverse psychological consequences among healthcare workers, especially those working in emergency departments.

Methods: Cross-sectional survey with purposive sampling was conducted. In this report, 96 obstetrics and gynaecology residents from India took part. The participants filled out a 61 item questionnaire to determine the psychological effect of COVID-19 on obstetrics and gynaecology residents in an online survey.

Results: $22.9 \%$ of residents were tested RT-PCR positive to SARS-CoV2. 52.1\% were reported they received an adequate quantity of personal protective equipment (PPE). $71.9 \%$ and $68.8 \%$ of residents have claimed that the number of elective cases/procedures and average OPD footfall per month respectively have decreased during this pandemic. $72.9 \%$ of residents have reported a reduction in teaching and academic activities. Of all the participants $66.7 \%$ had stress, $68.7 \%$ had anxiety while $61.5 \%$ had symptoms of depression. According to the Kessler distress scale, $37.5 \%$ of residents are likely to have a serious mental disorder. $42.7 \%$ of respondents were reported to suffer from moderate to severe clinical insomnia. The FCV-19 scale mean score was $18.79 \pm 6.782$ suggesting a mild to moderate level of fear of the ongoing pandemic. Anxiety, depression, fear, psychological distress and insomnia were all strongly correlated to stress $(\mathrm{p}<0.001)$.

Conclusions: The study highlights the urgency in dealing with the psychological wellbeing of healthcare professionals, especially in overburdened emergency services departments like obstetrics and gynaecology in such an overwhelming pandemic scenario.

Keywords: COVID-19, Stress anxiety depression, Insomnia, Psychological distress, Fear, Medical residents, India

\section{INTRODUCTION}

A newly emerging coronavirus-2 (SARS-CoV2) is responsible for COVID-19. ${ }^{1}$ COVID-19 is associated with detrimental health, socio-economic and psychological consequences. $^{2-4}$ COVID-19 is accepted as a pandemic by the WHO. ${ }^{5}$ The mental health of healthcare workers, especially those working in an emergency department can be adversely affected by this pandemic. ${ }^{6}$

Outpatient appointments, elective surgeries for non-urgent health problems being postponed all over the world. ${ }^{1}$ Although maternity services continue at the same levels compared to the pre-COVID period as the number of 
pregnant women who are considered one of the high-risk groups are being increasingly infected with the virus day by day. ${ }^{7}$ Therefore obstetricians play an important role in addressing this crisis.

The obstetrics and gynaecology residency training program has one of the largest, heterogeneous programs, in which acquisition of clinical, surgical and emergency management skills is mandatory. Among the obstetrics and gynaecology residents in India, the COVID-19 pandemic continues to have a considerable negative impact on their training program. The residents' exposure to skill training was grossly reduced as a result of a decrease in the number of outpatients visits, cessation of service provision to benign condition by hospitals, lockdowns, social isolation, long working hours in protective equipment, low clinical and surgical exposure, decreased academic activities, fear of contagion with COVID-19 positive patient among others leading to psychological stress among the residents. ${ }^{8}$

This study aimed to investigate the psychological effects of the COVID-19 pandemic on obstetrics and gynaecology residency in India.

\section{METHODS}

This study was an online cross-sectional survey with purposive sampling.

The inclusion criteria included participants from the obstetrics and gynaecology department enrolled in the residency training program in medical colleges across India, giving informed consent and a duly completed survey questionnaire.

Residents who did not give consent or submitted incomplete survey forms were excluded from the study.

An online survey was prepared with a 61 item questionnaire consisting of 7 socio-demographic questions, 9 questions on clinical exposure, 21 questions from the depression anxiety stress scale (DASS-21 Scale), 10 questions from Kessler psychological distress scale (K10), 7 questions from insomnia severity index scale (ISI) and 7 questions from fear of COVID-19 scale (FC19S). ${ }^{9-12}$

Data collection was done via google forms and the link to the questionnaire was sent to the residents on online platforms like whatsapp, facebook messenger, email. 96 participants out of 180 invited residents, who gave their consent and completed the survey were included in the study.

Statistical analysis was done using SPSS 25.0 software. Descriptive analysis was applied to calculate frequencies and proportions. Numerical data were presented as mean and standard deviation or a number (percentage). Spearman's correlation was used to determine the association between the parameters.

\section{DASS-21 scale}

The DASS is a quantitative measure of distress along 3 axes of depression, anxiety, stress. The DASS-21 has 21 items in 3 subscales of 7 items each. They ask about depressive symptoms (hopelessness, devaluation of life, self-deprecation, lack of interest, pessimistic about future), anxiety symptoms (autonomic arousal skeletal muscle effect, situation anxiety, worried about performance) and general stress symptoms (it assesses difficulty relaxing, nervous arousal, being easily upset, irritable, touchy). Response options are on a 4-point Likert scale (0-did not apply to me at all to 3-applied to me very much). Higher scores indicate higher psychological distress.

\section{Kessler psychological distress scale (K-10)}

Kessler psychological distress scale is a simple measure of psychological distress. The K-10 scale involves 10 questions about emotional states each with a five-level response scale. The measure can be used as a brief screen to identify the level of distress. Each item is scored from 1 (none of the time) to 5 (all of the time) and scores of 10 items are then summed, yielding a minimum score of 10 and a maximum score of 50. Low scores indicate low levels of psychological distress and a high score indicates high levels of psychological distress.

\section{Insomnia severity index (ISI)}

The insomnia severity index is a 7 item self-report questionnaire assessing the nature, severity and impact of insomnia. The usual recall period is the last month. A 5point Likert scale is used to rate each item ( 0 -no problem to 4-very severe problem), yielding a total score ranging from $0-28$. The score is interpreted as follows absence of insomnia (0-7), sub-threshold insomnia (8-14), moderate insomnia (15-21) and severe insomnia (22-28).

\section{Fear of COVID-19 scale}

The fear of COVID-19 scale is a unidimensional scale that assesses the fear of COVID-19. The scale comprises 7 items which are responded to on a 5-point Likert scale from 1 (strongly disagree) to 5 (strongly agree). The score that can be obtained from this scale varies between 7 and 35 and higher scores indicate greater fear of COVID-19.

\section{RESULTS}

\section{Study population}

180 Indian residents in obstetrics and gynaecology from different medical colleges of India were invited to participate in the study by e-mail as well as social media platforms like whatsapp and facebook. Out of the 180 residents, $96(53.3 \%)$ gave their consent and completed the survey. 
Table 1 shows the socio-demographic data of the participants. 57 participants were from the age group of 24-28 years $(59.4 \%), 32$ were from the 29-33 years age 84 of the respondents were female $(87.5 \%)$ and 12 were male $(12.5 \%) .69$ of the respondents were junior residents who were undergoing the residency training program $(71.9 \%)$ and 27 were senior residents $(28.1 \%)$ who had completed their M. D./diploma/D. N. B. in obstetrics and gynaecology degree and were in the training program. The majority of the residents were pursuing their residency training from Delhi NCT 27 (28.1\%) and Jharkhand 25 $(26 \%)$. The marital status showed that 42 residents were married $(43.8 \%)$ and 54 were unmarried $(56.3 \%)$. group (33.3\%) and 7 residents were from the age group of $34-38$ years $(7.3 \%)$. The mean age was $28.71 \pm 2.84$ years.

80 residents $(83.3 \%)$ were tested on real-time reverse transcriptase-polymerase chain reaction (RT-PCR) assay of nasal and oropharyngeal swab specimens for COVID19. Out of these eighty residents, 22 (22.9\%) residents were diagnosed with SARS-CoV2 infection and were RTPCR positive. The availability of PPE and other necessary protective equipment at the workplace showed that 50 residents $(52.1 \%)$ reported having received an adequate quantity of PPE, N-95 masks, while 40 (41.7\%) reported an inadequate supply.

Table 1: Socio-demographic data of the obstetrics and gynaecology residents in India.

\begin{tabular}{|c|c|c|c|}
\hline Sociodemographic variables & & Residents $(\mathrm{N}=96)$ & Percentage \\
\hline \multirow{3}{*}{ Age group (in years) } & $24-28$ & 57 & 59.4 \\
\hline & $29-33$ & 32 & 33.3 \\
\hline & $34-38$ & 7 & 7.3 \\
\hline \multirow{2}{*}{ Gender } & Female & 84 & 87.5 \\
\hline & Male & 12 & 12.5 \\
\hline \multirow[t]{2}{*}{ Professional qualification } & $\begin{array}{l}\text { Residents (M. D./M. } \\
\text { S./D. G. O./D. N. B. in } \\
\text { obstetrics and } \\
\text { gynaecology) }\end{array}$ & 69 & 71.9 \\
\hline & Senior Residents & 27 & 28.1 \\
\hline \multirow{4}{*}{ Indian state of residence } & Delhi NCT & 27 & 28.1 \\
\hline & Jharkhand & 25 & 26.0 \\
\hline & Uttar Pradesh & 15 & 15.6 \\
\hline & Other States & 29 & 30.3 \\
\hline \multirow{2}{*}{ Marital status } & Married & 42 & 43.8 \\
\hline & Unmarried & 54 & 56.3 \\
\hline \multirow{2}{*}{$\begin{array}{l}\text { Have you undergone RT-PCR testing for COVID- } \\
\text { 19? }\end{array}$} & Yes & 80 & 83.3 \\
\hline & No & 16 & 16.7 \\
\hline \multirow{2}{*}{$\begin{array}{l}\text { Have you been diagnosed with COVID-19 during } \\
\text { the pandemic? }\end{array}$} & Yes & 22 & 22.9 \\
\hline & No & 74 & 77.1 \\
\hline \multirow{3}{*}{$\begin{array}{l}\text { Availability of PPE kit, N95 masks and other } \\
\text { necessary protective equipment at your } \\
\text { workplace? }\end{array}$} & Adequate & 50 & 52.1 \\
\hline & Inadequate & 40 & 41.7 \\
\hline & Don't know & 6 & 6.3 \\
\hline
\end{tabular}

Table 2: Psychological analysis of the residents using DASS-21 scale, K-10 scale, ISI and fear of COVID-19 scale (FC19S).

\begin{tabular}{|c|c|c|c|c|}
\hline Scale & Grading & $\mathrm{N}=96$ & $\%$ & Mean \pm SD \\
\hline \multirow{5}{*}{ DASS-21 stress } & Normal & 32 & 33.3 & \multirow{5}{*}{$16.74 \pm 10.637$} \\
\hline & Mild & 26 & 27.1 & \\
\hline & Moderate & 19 & 19.8 & \\
\hline & Severe & 13 & 13.5 & \\
\hline & Extremely Severe & 6 & 6.3 & \\
\hline \multirow{5}{*}{ DASS-21 anxiety } & Normal & 30 & 31.3 & \multirow{5}{*}{$15.58 \pm 11.480$} \\
\hline & Mild & 5 & 5.2 & \\
\hline & Moderate & 20 & 20.8 & \\
\hline & Severe & 3 & 3.1 & \\
\hline & Extremely Severe & 38 & 39.6 & \\
\hline \multirow{2}{*}{ DASS-21 depression } & Normal & 37 & 38.5 & \multirow{2}{*}{$16.60 \pm 12.404$} \\
\hline & Mild & 4 & 4.2 & \\
\hline
\end{tabular}




\begin{tabular}{|c|c|c|c|c|}
\hline Scale & Grading & $\mathrm{N}=96$ & $\%$ & Mean \pm SD \\
\hline & Moderate & 15 & 15.6 & \\
\hline & Severe & 14 & 14.6 & \\
\hline & Extremely Severe & 26 & 27.1 & \\
\hline \multirow{4}{*}{$\begin{array}{l}\text { Kessler distress } \\
\text { scale }\end{array}$} & Likely to be well & 41 & 42.7 & \multirow{4}{*}{$25.11 \pm 11.454$} \\
\hline & $\begin{array}{l}\text { Likely to have a mild mental } \\
\text { disorder }\end{array}$ & 9 & 9.4 & \\
\hline & $\begin{array}{l}\text { Likely to have moderate } \\
\text { mental disorder }\end{array}$ & 10 & 10.4 & \\
\hline & $\begin{array}{l}\text { Likely to have a severe } \\
\text { mental disorder }\end{array}$ & 36 & 37.5 & \\
\hline \multirow{4}{*}{$\begin{array}{l}\text { Insomnia severity } \\
\text { index }\end{array}$} & $\begin{array}{l}\text { No clinically significant } \\
\text { insomnia }\end{array}$ & 33 & 34.4 & \multirow{4}{*}{$11.99 \pm 8.040$} \\
\hline & Subthreshold Insomnia & 22 & 22.9 & \\
\hline & $\begin{array}{l}\text { Clinical insomnia (moderate } \\
\text { severity) }\end{array}$ & 28 & 29.2 & \\
\hline & Clinical insomnia (severe) & 13 & 13.5 & \\
\hline \multicolumn{4}{|c|}{ Fear of COVID-19 scale } & $18.79 \pm 6.782$ \\
\hline
\end{tabular}

Table 3: Spearman's correlation between age, DASS-21 subscales, fear of COVID-19 scale, K-10 scale and ISI scales.

\begin{tabular}{|c|c|c|c|c|c|c|}
\hline \multicolumn{2}{|l|}{ Spearman's correlation } & $\begin{array}{l}\text { DASS- } \\
21 \\
\text { anxiety }\end{array}$ & $\begin{array}{l}\text { DASS-21 } \\
\text { depression }\end{array}$ & $\begin{array}{l}\text { Fear of } \\
\text { COVID- } \\
19 \text { scale }\end{array}$ & $\begin{array}{l}\mathrm{K}-10 \\
\text { scale }\end{array}$ & $\begin{array}{l}\text { Insomnia } \\
\text { severity } \\
\text { index }\end{array}$ \\
\hline Age & \multirow{6}{*}{$\mathrm{P}$} & & & $0.214^{*}$ & & \\
\hline DASS-21 stress & & $0.829^{* *}$ & $0.844^{* *}$ & $0.575^{* *}$ & $0.758^{* *}$ & $0.607^{* *}$ \\
\hline DASS-21 anxiety & & & $0.886^{* *}$ & $0.604^{* *}$ & $0.771^{* *}$ & $0.551^{* *}$ \\
\hline $\begin{array}{l}\text { DASS-21 } \\
\text { depression }\end{array}$ & & & & $0.542^{* *}$ & $0.799^{* *}$ & $0.595^{* *}$ \\
\hline $\begin{array}{l}\text { Fear of COVID-19 } \\
\text { scale }\end{array}$ & & & & & $0.638^{* *}$ & $0.444^{* *}$ \\
\hline K-10 scale & & & & & & $0.741^{* *}$ \\
\hline
\end{tabular}

*Significance at $\mathrm{p}<0.05$ ( 2 tailed); $* *$ significance at $\mathrm{p}<0.001$ ( 2 tailed); $\mathrm{N}=96 ; \mathrm{P}=$ correlation coefficient.
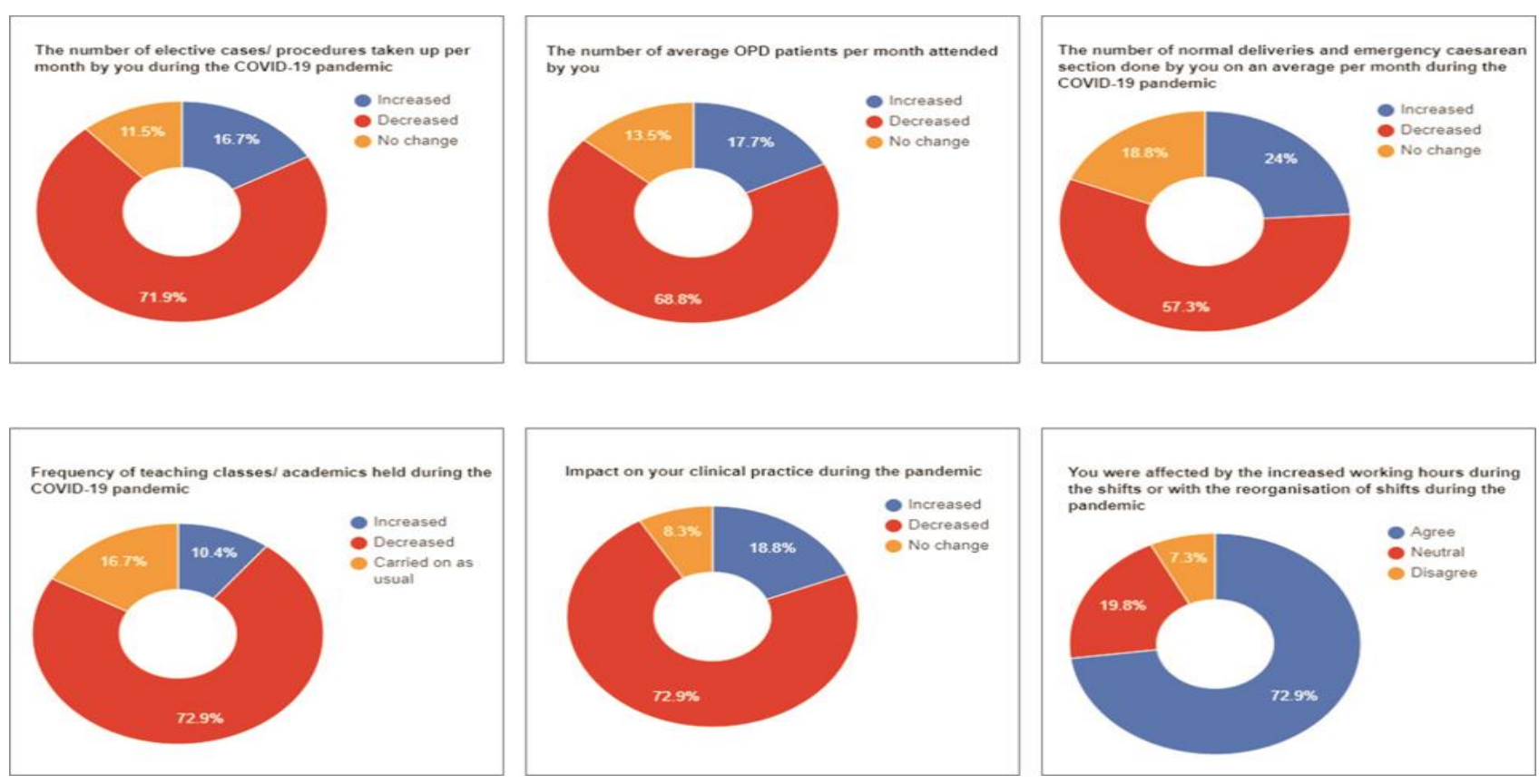

Figure 1: Clinical impact survey data. 


\section{Clinical survey results}

Figure 1 depicts that $71.9 \%$ of the residents reported a decrease in the number of elective cases/procedures per month during the pandemic well as $68.8 \%$ of residents noted a decrease in the number of average OPD patients per month during this time. 57.3\% have reported a decrease in the number of normal deliveries and emergency cesarean section, whereas $24 \%$ of the residents reported an increase in the number of normal deliveries and cesarean section cases in their medical college during this pandemic. $72.9 \%$ of the residents have reported a reduction in the frequency of teaching and academic activities during the COVID-19 pandemic. The beneficial impact on the residents' clinical practice has been decreased in $72.9 \%$ of the residents. Also, $72.9 \%$ of the residents agreed to the fact of being affected by the increased working hours and/or the reorganization of shifts.

\section{Psychological survey}

The psychological assessment of the residents is presented in Table 2. Of all participants, the DASS-21 scale highlighted that $66.7 \%$ of the respondents showed stress (mean score $=16.74 \pm 10.637$ ), $68.7 \%$ had anxiety (mean score $=15.58 \pm 11.480)$ and $61.5 \%$ had symptoms of depression (mean score $=16.60 \pm 12.404$ ). For the stress subscale in DASS-21, $27.1 \%$ of the sample reported mild stress symptoms, $19.6 \%$ reported moderate stress and $13.5 \%$ were reported severe, while $6.3 \%$ were reported extremely severe stress symptoms. The anxiety subscale depicted that $5.2 \%$ of the participants had mild anxiety symptoms, $20.8 \%$ had moderate, $3.1 \%$ were having severe and $39.6 \%$ were considered to have extremely severe anxiety symptoms. For the depression subscale, $4.2 \%$ of the study sample was reported to have mild depressive symptoms, $15.6 \%$ were reported to have moderate symptoms, $14.6 \%$ were reported to have severe and finally, $27.1 \%$ were reported to have extremely severe depressive symptomatology.

According to the K-10,57.3\% of residents showed features of distress (mean score $=25.11 \pm 11.454$ ). 9.4\% of the participants exhibited a mild level of distress with likely features of mild mental disorder, while $10.4 \%$ and $37.5 \%$ of the residents showcased moderate distress and severe distress respectively depicting a likely moderate and severe mental disorder.

The ISI highlighted that $65.6 \%$ of the residents suffered from insomnia (mean score $=11.99 \pm 8.040$ ). $22.9 \%$ of the residents presented with subthreshold insomnia, while $29.2 \%$ had moderately severe insomnia and $13.5 \%$ of residents had features of severe clinical insomnia.

On the FCV-19 scale, the mean score was $18.79 \pm 6.782$ suggesting a mild to moderate level of fear from the SARS-CoV2 infection.

\section{Non-parametric correlation}

Spearman's correlation analysis is shown in Table 3 . The age of the participants is positively correlated with the fear of COVID-19 scale $(p<0.05)$. The DASS-21 stress subscale is very positively correlated with DASS-21 anxiety, depression subscales, along with the fear of COVID-19 scale, K-10 scale and ISI $(p<0.001)$. The DASS-21 subscale is positively correlated with the depression subscale, fear of COVID-19 scale, K-10 scale, and ISI $(p<0.001)$. The DASS-21 depression subscale is positively correlated with the fear of COVID-19 scale, K10 scale and ISI $(p<0.001)$. The fear of COVID-19 scale is positively correlated with the K-10 scale and ISI $(\mathrm{p}<0.001)$. The $\mathrm{K}-10$ scale is positively correlated with ISI $(\mathrm{p}<0.001)$.

\section{DISCUSSION}

This cross-sectional study aimed to evaluate the psychological impact of COVID-19 on the residents from the obstetrics and gynaecology department from various medical colleges of India. The survey was based on questionnaire results from the 96 participants from the residency program in India. To the best of our knowledge, it might be the first study accessing the impact of the pandemic on a specific department in its first and second waves. The majority of the respondents were unmarried females. The mean age was $28.71 \pm 2.839$ years.

80 residents $(83.3 \%)$ have undergone RT-PCR testing, out of which $22(22.9 \%)$ have been tested positive for the virus during the pandemic. This is quite higher as compared to a previous study done on Italian obstetrics and gynaecology residents where $38.6 \%$ of the residents were tested and only $6.5 \%$ were positive. ${ }^{1}$ This can be attributed to the fact that our study included the ongoing second wave of the pandemic. $52.1 \%$ of residents reported that they had an adequate supply of PPE while $41.7 \%$ felt there was an inadequate supply at their workplace. The previous study shows $56.1 \%$ of the residents had an adequate supply of PPE. ${ }^{1}$

In the clinical exposure, the residents $(71.9 \%)$ reported a decrease in the number of elective surgeries and procedures undertaken per month during the pandemic. A study on orthopedic residents from Delhi-NCR found out that $92 \%$ of the respondents expressed a reduction in the number of surgical and elective procedures during the pandemic. ${ }^{13}$ In another study on European obstetrics and gynaecology trainees, $67 \%$ of them reported a reduction in surgical skill training along with a decrease in workload and lecture activities. ${ }^{14} 68.8 \%$ residents responded that the average OPD attendance was grossly reduced during the pandemic which is also agreed upon in similar studies. ${ }^{1,13}$

$72.9 \%$ of the residents in our study have reported a reduction in the teaching and academic activities in this crisis period. It is found to be agreed upon in similar studies on residents. ${ }^{1,13,15,16}$ These studies have also 
relatable responses to the decrease in clinical practices that the residents need to undergo during their training program.

In our study, $66.7 \%$ of respondents suffer from stress, $68.7 \%$ of the respondent from anxiety and $61.5 \%$ of respondents were found to suffer from depression. While in a study conducted on healthcare workers in Singapore, the prevalence for stress, anxiety and depression in medical health personnel was found to be $6.4 \%, 14.5 \%$, and $8.1 \%$ respectively. ${ }^{17}$ In another Indian study, the prevalence for stress, anxiety and depression in medical health workers were reported $9.5 \%, 19.5 \%$, and $17 \%$ respectively. ${ }^{18} \mathrm{~A}$ study conducted in the Iranian population showed that the medical students had a higher score of stress, anxiety and depression than other medical staff or patients and the general population. ${ }^{19} \mathrm{~A}$ study on Chinese healthcare workers in the paediatric department reported stress, anxiety and depression scores of $9.98 \%, 18.3 \%$ and $14.81 \%$ respectively and found to be affecting more to male doctors above 31 years of age. ${ }^{20}$ An Indian study on first year medical students reported the DASS-21 scores to be $15.6 \%, 17.20 \%$ and $10.80 \%$ for stress, anxiety and depression respectively. ${ }^{21}$ The increased stress, anxiety and depression observed from the DASS-21 scale in our study indicated the emergency nature of duties by the residents, increased work hours and other extrinsic and intrinsic pressures in the training program.

In our study, $57.3 \%$ of respondents were to suffer from psychological distress. $9.4 \%, 10.4 \%, 37.5 \%$ were in the mild, moderate and severe psychological distress categories. In the study on Ethiopian healthcare professionals, the psychological distress during this pandemic was found out to be $42 \%$ and it was $18 \%, 11 \%$, $13 \%$ for the mild, moderate and severe category respectively in the Kessler rating scale. ${ }^{22}$ An Egyptian survey of physicians reported $50 \%$ of their healthcare workers, predominantly female to be in severe distress during the pandemic while working with a COVID-19 patient. $^{23}$ Another study on healthcare workers from Jordan found that $20 \%$ of the participants' mainly younger females, dissatisfied with their work had severe distress. ${ }^{24}$ In our study, the residents showed a higher percentage of moderate to severe psychological distress which may be to the fact that the clinical exposure of the residents has reduced along with other academic activities.

$65.6 \%$ of respondents in our study were found to suffer from significantly higher insomnia. $29.2 \%$ of the respondents suffered from moderate severity clinical insomnia while $13.5 \%$ of the participants reported suffering from severe clinical insomnia. In another study from Chinese medical staff, the prevalence of insomnia among healthcare workers was $30 \%$ and a study during the early phase of the pandemic also highly suggested the symptoms of insomnia of the healthcare workers in the frontline in China. ${ }^{25,26}$ A study on Nepalese healthcare workers reported that $33.9 \%$ suffered from insomnia. ${ }^{27}$ Also, it was reported from a study in China that women healthcare workers were more vulnerable to clinical insomnia than their male counterparts during the pandemic. ${ }^{28}$ A previous study on the psychological impact of COVID-19 on Indian anaesthesiologists reported a high prevalence of insomnia in $60.5 \%$ of the respondents. ${ }^{29}$

The mean score for the fear of COVID-19 scale in our study was $18.79 \pm 6.782$, while a reported the FC19S mean score to be $22.3 \pm 6.1$ and $21.6 \pm 6.6$ among the Israeli and Russian students in the first coronavirus wave and $22.6 \pm 5.8$ and $21.8 \pm 6.4$ respectively in the second wave. ${ }^{30}$ Another study among the healthcare professionals in Mexico found that the mean fear score was $19.3 \pm 6.9$ which was higher as compared to our study. ${ }^{31}$ In another study conducted in Brazil, the FC19S mean score was reported to $19.8 \pm 5.3$ and indicated high levels of fear among females in the age group 18-29 years and belonging in high-risk groups. ${ }^{32} \mathrm{~A}$ study on healthcare workers in Bangladesh suggested that females had a higher fear of COVID-19 and higher depression features as a result. ${ }^{33}$ Another study on the doctors and postgraduate trainees in Pakistan highlighted the fear of COVID-19 was significantly higher in female postgraduate trainees, doctors who had less than 5 years of experience along with high levels of workplace phobia, panic, anxiety and work avoidance behaviours. ${ }^{34}$

Spearman correlation was used to analyze the association between different groups. The age of the resident trainees was positively correlated with the fear of COVID-19 scale $(\mathrm{p}=0.214 *, \mathrm{p}<0.05)$. Studies from Pakistan and Brazil show that younger age groups with high vulnerability to COVID-19 have a higher fear of COVID-19 than those at a higher age group. ${ }^{32,34}$ This is mainly because they are less experienced in facing such a circumstance along with the fear of being infected with the contagion. The DASS-21 stress subscale was positively correlated to anxiety and depression subscales $(\mathrm{p}=0.829 * *$ and $\mathrm{p}=0.844 * *$, $\mathrm{p}<0.001)$ respectively. Stress was also correlated with fear of COVID-19 scale ( $\left.\mathrm{p}=0.575^{* *}, \mathrm{p}<0.001\right), \mathrm{K}-10$ scale $\left(\mathrm{p}=0.758^{* *}, \mathrm{p}<0.001\right)$, and ISI $(\mathrm{p}=0.607 * *, \mathrm{p}<0.001)$. Several studies from India, China, United Kingdom, Malaysia, Pakistan, Nepal have suggested a prevalence of stress, anxiety, depression, fear, insomnia and other symptoms like somatization, burnout, obsessivecompulsive behavior. ${ }^{26,27,29,34-37}$ Anxiety was positively correlated to depression subscales $\left(\mathrm{p}=0.886^{* *}, \mathrm{p}<0.001\right)$, fear of COVID-19 scale ( $\mathrm{p}=0.604 * *, \mathrm{p}<0.001), \mathrm{K}-10$ scale $\left(\mathrm{p}=0.771^{* *}, \mathrm{p}<0.001\right)$ and ISI $\left(\mathrm{p}=0.551^{* *}, \mathrm{p}<0.001\right)$. Studies have also found a link between anxiety and associated psychological impacts in COVID-19. ${ }^{23,34,38,39}$ The positive correlation between depression and fear of COVID-19 scale $(\mathrm{p}=0.542 * *, \mathrm{p}<0.001), \mathrm{K}-10$ scale $(\mathrm{p}=0.799 * *, \mathrm{p}<0.001)$ and ISI $(\mathrm{p}=0.595 * *, \mathrm{p}<0.001)$. Studies show an association of depression with fear of infection, distress and loss of quality sleep..$^{18,23,33,40}$ Fear of COVID-19 is positively correlated with psychological distress $\left(\mathrm{p}=0.638^{* *}, \mathrm{p}<0.001\right)$ as well as insomnia $(\mathrm{p}=0.444 * *, \mathrm{p}<0.001)$ which is also observed in similar studies. ${ }^{18,22,25,29}$ The Kessler psychological distress scale is 
positively correlated with ISI $(\mathrm{p}=0.741 \% * *, \mathrm{p}<0.001)$. Previous study associates distress as a major factor for insomnia leading to burnout among healthcare professionals. $^{23}$

COVID-19 has added a dense layer of psychological stress on the previous prevailing conditions on the medical residents even before the pandemic. In the pre-COVID times, a Malaysian study in 2018 highlighted that there were stressors like examinations, high workload, financial responsibilities, stigma and complexity of the medical care among others which led to stress, anxiety, depression, burnout, substance use. ${ }^{41}$ Female doctors were also found to be more affected than their male colleagues.

A previous Indian study showed that stress, anxiety and depression among resident doctors were $24.24 \%, 36.58 \%$, and $27.71 \%$ respectively. ${ }^{42}$ Long work hours, a heavy workload, the lack of a hobby and a poor level of control over the job were all factors in their findings. They also reported that the surgical residents had a higher level of stress than the residents of non-surgical branches. Another study from Brazil in 2017 reported $17.7 \%$ stress, anxiety symptoms in $16 \%$ and depression symptoms in $19 \%$ of the resident sample. Burnout syndrome was seen in $63 \%$ of the study sample which had a negative correlation to their quality of life. ${ }^{43}$

The studies from Iran in 2011 reported mean K-10 scores of $23.5 \pm 7.2$ which were slightly lower than our study. ${ }^{44}$ While a Canadian study from 2015 had the mean K-10 score as $19.5 \pm 6.25$ where academic stressors and substance use were the main cause. ${ }^{45}$ Another study from Australia in 2016 reported the mean K-10 score as 17.2 \pm 6.3 among junior doctors and attributed their findings to high working hours and increased responsibilities. ${ }^{46}$

Medical students are a favourite group for insomnia researchers and many studies have been conducted to assess the level of insomnia and its stressors. A study from Iran in 2014 reported the mean score of the ISI as $9.79 \pm 5.03$ among medical students. ${ }^{47}$ While a study in Egypt in 2016 noted the mean insomnia score as $10.84 \pm 7.15$ and insomnia was present in $27.7 \%$ of the students. ${ }^{48}$ Another study from Jordan in 2019 highlighted the mean score as $11.2 \pm 5.2$ and $26 \%$ of the participants suffered from moderate to severe clinical insomnia. ${ }^{49}$ Stress, anxiety and depression were reported to be the main factors for sleep deprivation and diminished quality of sleep.

These studies have shown a high level of stress, anxiety and depression among the resident doctors which may act as a baseline and our study reports comparatively very high levels of psychological impact which can be directly connected to the ongoing pandemic.

\section{Limitations}

This study had some limitations. First, the sample population was of a very limited group and the availability at such a time was low. Then, psychological assessments on depression, anxiety, insomnia, fear and distress were evaluated by online questionnaire, rather than a psychiatric interview which might lead to less reliable data. Thirdly, past psychiatric illness history could not be obtained. Lastly, this article was a cross-sectional study, whereas longitudinal research was needed for the prevalence of these mental states.

\section{CONCLUSION}

Due to the COVID-19 pandemic, frontline healthcare workers will be at higher psychological risk, especially in emergency services departments. Among the Indian obstetrics and gynaecology residents, the COVID-19 pandemic has had a considerable negative impact on the residency training programs. The residents' exposure to proficient training and clinical exposure was drastically reduced as a result of a decrease in the number of outpatient visits and cessation of the provision of services for benign conditions like infertility cases, oncology screening, colposcopy training and gynaecological surgeries by hospitals. These factors, along with increased working hours, fear of contagion during invasive and noninvasive procedures with a COVID-19 positive patient, lack of sleep and an overburdened and outstretched work environment is leading to undesired psychological outcomes. The second wave of COVID-19 has brought with it new challenges.

Therefore, new organizational strategies are necessary to minimize training deficiencies and remove the barriers to better psychological wellbeing. Innovative solutions like teleconsultations, use of virtual academic sessions, promotion of health and hygiene are needed to nurture a conducive learning environment needs to be implemented. Regular psychological evaluation of residents in emergency and high-risk departments is needed as well as the implementation of policies to avoid significant mental health issues and occupational risks. The effect of COVID19 on mental health must be mitigated by facilitating and ensuring the psychological well-being of healthcare workers both during and after the pandemic.

\section{Recommendations}

Our results can be applied to other high-risk and emergency departments and future research can be conducted in other departments as well so that stressors can be minimized and encourage the psychological wellbeing of frontline healthcare staff all while building a balanced work environment. 


\section{ACKNOWLEDGMENTS}

The authors would like to thank all the obstetrics and gynaecology residents from various Indian medical colleges who gave their valuable time to complete the questionnaire. Special thanks to Dr. Divyani Agrawal who helped in the distribution of the questionnaire and data collection. We would like to thank Hariom Pachori for helping in statistical analysis and Deepika Lina Minz for helping in the final editing and formatting of the paper.

\section{Funding: No funding sources}

Conflict of interest: None declared

Ethical approval: The study was approved by the Institutional Ethics Committee

\section{REFERENCES}

1. Bitonti G, Palumbo AR, Gallo C, Rania E, Saccone G, Vivo VD, et al. Being an obstetrics and gynaecology resident during the COVID-19: Impact of the pandemic on the residency training program. Eur $\mathrm{J}$ Obstet Gynecol Reprod Biol. 2020;253:48-51.

2. Perlman S. Another decade, another coronavirus. N Engl J Med. 2020;382(8)760-2.

3. Lipsitch M, Swerdlow DL, Finelli L. Defining the Epidemiology of COVID-19-studies needed. N Engl J Med. 2020;382(13):1194-6.

4. Saccone G, Florio A, Aiello F, Venturella R, Angelis MCD, Locci M, et al. Psychological impact of coronavirus disease 2019 in pregnant women. Am J Obstet Gynecol. 2020;223(2):293-5.

5. Mahato C, Suryavanshi S. Knowledge, attitude and practices towards COVID-19 among nurses, ward attendants, and housekeeping staff at a tertiary psychiatric institute in India. Int J Community Med Public Heal. 2020;7(12):5035.

6. Fiorillo A, Gorwood P. The consequences of the COVID-19 pandemic on mental health and implications for clinical practice. Eur Psychiatry. 2020;63(1):32.

7. Mirzadeh M, Khedmat L. Pregnant women in the exposure to COVID-19 infection outbreak: the unseen risk factors and preventive healthcare patterns. J Matern Neonatal Med. 2020:1-2.

8. Uzun ND, Tekin M, Sertel E, Tuncar A. Psychological and social effects of COVID-19 pandemic on obstetrics and gynecology employees. J Surg Med. 2020;4(5):355-8.

9. Lovibond SH, Lovibond PF. Manual for the Depression Anxiety Stress Scales. 2nd ed. Sydney: Psychology Foundation of Australia; 1995.

10. Kessler RCMD, Mroczek D. An update of the development of mental health screening scales for the US national health interview study. Ann Arbor Univ Michigan. 1992.

11. Bastien $\mathrm{CH}$, Vallières $\mathrm{A}$, Morin $\mathrm{CM}$. Validation of the insomnia severity index as an outcome measure for insomnia research. Sleep Med. 2001;2(4):297-307.
12. Ahorsu DK, Lin C, Imani V, Saffari M, Griffiths MD, Pakpour AH. The fear of COVID-19 Scale: development and initial validation. Int J Ment Health Addict. 2020:1-9.

13. Kumar M, Vaish A. Journal of clinical orthopaedics and trauma impact of COVID-19 on post-graduate orthopaedic training in Delhi-NCR. J Clin Orthop Trauma. 2020;11:687-95.

14. Boekhorst F, Khattak H, Goknur E, Horala A. The influence of the COVID-19 outbreak on European trainees in obstetrics and gynaecology: a survey of the impact on training and trainee. Euro J Obstet Gynecol Reproduct Biol. 2021;261:52-8.

15. Gupta RR, Vaishnao LS, Shinde S, Singh I, Mishra T, Sharma K. Effect of lockdown due to COVID-19 pandemic on mental health of final year students of Maharashtra. Int J Community Med Public Heal. 2020;7(12):5100.

16. Griffin R, Norwitz ER, Ph D, Lancey JODE. Reengineering academic departments of obstetrics and gynecology to operate in a pandemic world and beyond-a joint AGOS/CUCOG statement. Am J Obstet Gynecol. 2020;223(3):383.

17. Tan BYQ, Chew NWS, Lee GKH, Jing M, Goh Y, Yeo LLL, et al. Psychological impact of the COVID19 pandemic on health care workers in Singapore. Ann Intern Med. 2020;173(4):317-20.

18. Mathur S, Sharma D, Solanki RK, Goyal MK. Stressrelated disorders in health-care workers in COVID-19 pandemic: a cross-sectional study from India. Ann Intern Med. 2020:1083.

19. Vahedian-Azimi A, Moayed M, Rahimibashar F, Shojaei S, Ashtari S, Pourhoseingholi M. Comparison of the severity of psychological distress among four groups of an Iranian population regarding COVID-19 pandemic. BMC Psychiatry. 2020;402(2020):1-7.

20. Liu Y, Wang L, Chen L, Bao L, Shi Y, Zhang X. Mental health status of paediatric medical workers in china during the COVID-19 outbreak. Front Psychiatry. 2020;11(2020):702.

21. Vala N, Vachhani M, Sorani A. Study of anxiety, stress and depression level among medical students during COVID-19 pandemic phase in Jamnagar city. Natl J Physiol Pharm Pharmacol. 2020;10:1.

22. Tsehay M, Belete A, Necho M. Factors associated with psychological distress and brief resilient coping level during the covid-19 pandemic among healthcare professionals in dessie, Ethiopia. Psychol Res Behav Manag. 2020;13.

23. Sehsah R, Hassan M, Abdel G, El H, Ahmed G. Psychological distress among Egyptian physicians during COVID-19 pandemic. Int Arch Occup Environ Health. 2021;94(4):731-40.

24. Hawari FI, Obeidat NA, Dodin YI. The inevitability of COVID-19 related distress among healthcare workers: findings from a low caseload country under lockdown. PloS One. 2021

25. Liu D, Liu S, Zhu L, Li D, Huang D, Deng H, et al. Prevalence and related factors of insomnia among 
chinese medical staff in the middle and late stage of COVID-19. Front Psychiatry. 2020;11:1-7.

26. Zhang W, Wang K, Zhao W, Xue Q. Mental health and psychosocial problems of medical health workers during the COVID-19 epidemic in China. 2020;100053(45):242-50.

27. Khanal P, Devkota N, Dahal M, Paudel K, Joshi D. Mental health impacts among health workers during COVID-19 in a low resource setting: a crosssectional survey from Nepal. Glob Health. 2020;89:112.

28. Liu S, Yang L, Zhang C, Xu Y, Cai L, Ma S, et al. Gender differences in mental health problems of healthcare workers during the coronavirus disease 2019 outbreak. J Psychiatr Res. 2021;137:393-400.

29. Jain A, Singariya G, Kamal M, Kumar M, Jain A, Solanki RK. COVID-19 pandemic: psychological impact on anaesthesiologists. Indian $\mathrm{J}$ Anaesth. 2020;64(9):774-83.

30. Reznik A, Gritsenko V, Konstantinov V, Yehudai M, Bender S, Shilina I, et al. First and second wave covid19 fear impact: Israeli and Russian social work student fear, mental health and substance use. Int J Ment Health Addict. 2021:1-8.

31. García-Reyna B, Castillo-García GD, BarbosaCamacho FJ, Cervantes-Cardona GA, CervantesPérez E, Torres-Mendoza BM, et al. Fear of COVID19 scale for hospital staff in regional hospitals in mexico: a brief report. Int $\mathbf{J}$ Ment Health Addict. 2020:1-12.

32. Giordani RCF, Silva MZD, Giolo SR, Muhl C. Fear of COVID-19 scale: Assessing fear of the coronavirus pandemic in Brazil. J Health Psychol. 2020:1359105320982035.

33. Sakib N, Akter T, Zohra F, Bhuiyan AKMI. Fear of COVID-19 and Depression: A Comparative Study Among the General Population and Healthcare Professionals During COVID-19 Pandemic Crisis in Bangladesh. Int J Ment Health Addict. 2021.

34. Malik S, Ullah I, Irfan M, Ahorsu DK, Lin C, Pakpour AH. Fear of COVID-19 and workplace phobia among Pakistani doctors: a survey study. BMC Public Health. 2021;21:833.

35. Shah N, Raheem A, Sideris M, Velauthar L, Saeed F. Mental health amongst obstetrics and gynaecology doctors during the COVID-19 pandemic: Results of a UK-wide study. Eur J Obstet Gynecol Reprod Biol. 2020;253:90-4.

36. Fadhli M, Fauzi M, Mohd H, Robat RM. Doctors' Mental health in the midst of COVID-19 Pandemic: the roles of work demands and recovery experiences. Int J Environ Res Public Health. 2020;17(19):7340.

37. Wang H, Huang D, Huang H, Zhang J, Guo L, Liu Y. The psychological impact of COVID-19 pandemic on medical staff in Guangdong, China: a cross-sectional study. Psychol Med. 2020:1-9.

38. Zhao K, Zhang G, Feng R, et al. Anxiety, depression and insomnia: A cross-sectional study of frontline staff fighting against COVID-19 in Wenzhou, China. Psychiatry Res. 2020;292:113304.

39. Torales J, O'Higgins M, Castaldelli-Maia JM, Ventriglio A. The outbreak of COVID-19 coronavirus and its impact on global mental health. Int J Soc Psychiatry. 2020;66(4):317-20.

40. Duplaga M. the association between future anxiety, health literacy and the perception of the covid-19 pandemic: a cross-sectional study. MDPI. 2021;9(1):43.

41. Bhagat V, Haque M, Simbak NB, Husain R. Stress among medical students and advantages of metallisation therapy in general: a review of literatures. Adv Hum Biol. 2018;8(2):59-63.

42. Sarthak Dave, Minakshi Parikh, Ganpat Vankar SKV. Depression, anxiety, and stress among resident doctors of a teaching hospital. Indian J Soc Psychiatry. 2019;34(2):111-5.

43. Pasqualucci PL, Damaso LLM, Danila AH, Fatori D, Lotufo Neto F, Koch VHK. Prevalence and correlates of depression, anxiety, and stress in medical residents of a Brazilian academic health system. BMC Med Educ. 2019;19(1):1-5.

44. Koochaki GM, Charkazi A, Hasanzadeh A, Saedani M, Qorbani M, Marjani A. Prevalence of stress among Iranian medical students: a questionnaire survey. East Mediterr Heal J. 2011;17(7):593-8.

45. Matheson KM, Barrett T, Landine J, McLuckie A, Soh NLW, Walter G. Experiences of psychological distress and sources of stress and support during medical training: a survey of medical students. Acad Psychiatry. 2016;40(1):63-8.

46. Pan T, Fan HS, Owen CA. The work environment of junior doctors: their perspectives and coping strategies. Postgrad Med J. 2017;93(1101):414-9.

47. Vand HDA, Gharraee B, Farid AA, Bandi MFG. Prediction of insomnia severity based on cognitive, metacognitive, and emotional variables in college students. Explor J Sci Heal. 2014;10(4):233-40.

48. Barakat D, Elwasify M, Elwasify M, Radwan D. Relation between insomnia and stress, anxiety and depression among Egyptian medical students. Middle East Curr Psychiatry. 2016;23(3):119-27.

49. Alqudah M, Balousha SAM, Al-Shboul O, Al-Dwairi A, Alfaqih MA, Alzoubi KH. Insomnia among medical and paramedical students in Jordan: impact on academic performance. Biomed Res Int. 2019;2019:7136906.

Cite this article as: Prasad S, Mahato C, Magon N. Psychological impact of COVID-19 on obstetrics and gynaecology residents in India. Int J Reprod Contracept Obstet Gynecol 2021;10:2785-93. 